\title{
Cardiac Hypoxia Imaging: Second-Generation Analogues of ${ }^{64} \mathrm{Cu}-\mathrm{ATSM}$
}

\author{
Maxwell G. Handley, Rodolfo A. Medina, Erika Mariotti, Gavin D. Kenny, Karen P. Shaw, Ran Yan, Thomas R. Eykyn, \\ Philip J. Blower, and Richard Southworth
}

Division of Imaging Sciences and Biomedical Engineering, King's College London, London, United Kingdom

\begin{abstract}
Myocardial hypoxia is an attractive target for diagnostic and prognostic imaging, but current approaches are insufficiently sensitive for clinical use. The PET tracer copper(II)-diacetyl-bis (N4-methylthiosemicarbazone) $\left({ }^{64} \mathrm{Cu}-\mathrm{ATSM}\right)$ has promise, but its selectivity and sensitivity could be improved by structural modification. We have therefore evaluated a range of ${ }^{64} \mathrm{Cu}$-ATSM analogs for imaging hypoxic myocardium. Methods: Isolated rat hearts ( $n=5$ /group) were perfused with normoxic buffer for $30 \mathrm{~min}$ and then hypoxic buffer for $45 \mathrm{~min}$ within a custom-built triple- $\gamma$-detector system to quantify radiotracer infusion, hypoxiadependent cardiac uptake, and washout. A 1-MBq bolus of each candidate tracer (and ${ }^{18} \mathrm{~F}$-fluoromisonidazole for comparative purposes) was injected into the arterial line during normoxia, and during early and late hypoxia, and their hypoxia selectivity and pharmacokinetics were evaluated. The in vivo pharmacokinetics of promising candidates in healthy rats were then assessed by PET imaging and biodistribution. Results: All tested analogs exhibited hypoxia sensitivity within $5 \mathrm{~min}$. Complexes less lipophilic than ${ }^{64} \mathrm{Cu}$-ATSM provided significant gains in hypoxic-to-normoxic contrast (14:1 for ${ }^{64} \mathrm{Cu}-2,3$-butanedione bis(thiosemicarbazone) (ATS), 17:1 for ${ }^{64} \mathrm{Cu}-2,3-$ pentanedione bis(thiosemicarbazone) (CTS), 8:1 for $\left.{ }^{64} \mathrm{Cu}-\mathrm{ATSM}, P<0.05\right)$. Hypoxic first-pass uptake was $78.2 \% \pm 7.2 \%$ for ${ }^{64} \mathrm{Cu}-\mathrm{ATS}$ and $70.7 \% \pm 14.5 \%$ for ${ }^{64} \mathrm{Cu}$-CTS, compared with $63.9 \% \pm 11.7 \%$ for ${ }^{64} \mathrm{Cu}$-ATSM. Cardiac retention of ${ }^{18} \mathrm{~F}$-fluoromisonidazole increased from $0.44 \% \pm 0.17 \%$ during normoxia to $2.24 \% \pm 0.08 \%$ during hypoxia. In vivo, normoxic cardiac retention of ${ }^{64} \mathrm{Cu}$-CTS was significantly lower than that of ${ }^{64} \mathrm{Cu}$-ATSM and ${ }^{64} \mathrm{Cu}$-ATS $(0.13 \% \pm$ $0.02 \%$ vs. $0.25 \% \pm 0.04 \%$ and $0.24 \% \pm 0.03 \%$ injected dose, $P<0.05$ ), with retention of all 3 tracers falling to less than $0.7 \%$ injected dose within 6 min. ${ }^{64} \mathrm{Cu}$-CTS also exhibited lower uptake in liver and lung. Conclusion: ${ }^{64} \mathrm{Cu}-\mathrm{ATS}$ and ${ }^{64} \mathrm{Cu}-\mathrm{CTS}$ exhibit better cardiac hypoxia selectivity and imaging characteristics than the current lead hypoxia tracers, ${ }^{64} \mathrm{Cu}$-ATSM and ${ }^{18} \mathrm{~F}$-fluoromisonidazole.
\end{abstract}

Key Words: hypoxia; PET; ${ }^{64} \mathrm{Cu}-\mathrm{ATSM}$; bis(thiosemicarbazones); ${ }^{18} \mathrm{FMISO}$; cardiac ischemia

J Nucl Med 2014; 55:488-494

DOI: 10.2967/jnumed.113.129015

Received Jul. 11, 2013; revision accepted Oct. 10, 2013.

For correspondence or reprints contact: Richard Southworth, The Rayne Institute, St. Thomas' Hospital, Lambeth Palace Rd., London, SE1 7EH, U.K.

E-mail: richard.southworth@kcl.ac.uk.

Published online Jan. 13, 2014.

COPYRIGHT $\odot 2014$ by the Society of Nuclear Medicine and Molecular Imaging, Inc.
$\mathbf{T}$ issue hypoxia, as a facet of ischemia, is associated with many forms of cardiac dysfunction, including myocardial hibernation, noncompensated hypertrophy, microvascular disease, and heart failure $(1,2)$. Many of these conditions are difficult to identify or stratify using currently available technologies $(2,3)$. To expand our window for antiischemic intervention, it would be desirable to noninvasively detect the disturbances in cardiac biochemistry that precede the functional and morphologic changes that are currently identified by echocardiography, perfusion scintigraphy, or MR imaging. Hypoxia-specific PET or SPECT radiotracers represent an opportunity to do this by identifying myocardial regions in which oxygen demand exceeds supply, giving metabolic context to the more generic information gained by characterizing deficits in either perfusion or contractility (4).

Although hypoxia-selective nitroimidazole derivatives such as ${ }^{18}$ F-fluoromisonidazole, and the nonnitroimidazole complex ${ }^{99 \mathrm{~m}}$ Tc-HL91 ( ${ }^{99 \mathrm{~m}}$ Tc-labeled 4,9-diaza-3,3,10,10-tetramethyldodecan-2,11-dionedioxime), have been extensively investigated for applications in cancer imaging, their low first-pass uptake, slow blood clearance, and high liver uptake have meant that hypoxia imaging has failed to have a significant impact on clinical practice in cardiology $(3,4)$. The bis(thiosemicarbazone) (BTSC) complex copper(II)-diacetyl-bis(N4-methylthiosemicarbazone) $\left({ }^{64} \mathrm{Cu}\right.$-ATSM) has been shown to selectively deposit radiocopper in hypoxic cultured cells (5-9), in isolated perfused hearts (10), in vivo in implanted tumors (11), and in regionally ischemic myocardium in open-chest dogs (12). Although ${ }^{64} \mathrm{Cu}$-ATSM has been the subject of several promising clinical trials for applications in oncology $(13,14)$, its utility for cardiovascular imaging has been addressed in only a small clinical study of 7 patients, with equivocal results (15). Isolated cell studies suggest that ${ }^{64} \mathrm{Cu}$-ATSM accumulates in only those cells experiencing extracellular partial pressure of $\mathrm{O}_{2}$ below $1 \mathrm{~mm} \mathrm{Hg}(6)$, which, although suitable for identifying hypoxic tumors, may be more severely hypoxic than is typically evident in hypoxically compromised but salvageable myocardium. This limitation may explain its mediocre performance in this small clinical trial (3).

BTSC complexes are, however, highly modifiable in terms of redox potential and lipophilicity, with the potential to make them tuneable to different degrees of hypoxia for different applications or disease states. We have previously demonstrated the hypoxia selectivity of several complexes structurally related to ${ }^{64} \mathrm{Cu}-$ ATSM in isolated cancer cells in vitro $(5,6,16)$, but they have yet to be evaluated for cardiac application, and their relative pharmacokinetics in any dynamic model are currently unknown. In this study, 


\begin{tabular}{|c|c|c|c|c|c|c|c|c|}
\hline Complex & R1 & R2 & R3 & R4 & $\begin{array}{c}\text { Mol } \\
\text { weight }\end{array}$ & $\begin{array}{c}\mathrm{Rf} \\
\text { (ITLC) }\end{array}$ & $\begin{array}{l}\text { LogP } \\
\text { (octonol/ } \\
\text { water) }\end{array}$ & $\begin{array}{c}\text { LogP } \\
\text { (octonol/ } \\
\text { KHB) }\end{array}$ \\
\hline${ }^{64}$ Cu-ATS & $\mathrm{CH}_{3}$ & $\mathrm{CH}_{3}$ & $\mathrm{H}$ & $\mathrm{H}$ & 293.86 & 0.70 & 0.88 & 0.91 \\
\hline${ }^{64} \mathrm{CU}$-ATSE & $\mathrm{CH}_{3}$ & $\mathrm{CH}_{3}$ & $\mathrm{C}_{2} \mathrm{H}_{5}$ & $\mathrm{H}$ & 349.97 & 0.83 & 1.86 & 1.85 \\
\hline${ }^{64} \mathrm{CU}$-ATSM & $\mathrm{CH}_{3}$ & $\mathrm{CH}_{3}$ & $\mathrm{CH}_{3}$ & $\mathrm{H}$ & 321.91 & 0.79 & 1.69 & 1.72 \\
\hline${ }^{64} \mathrm{Cu}-\mathrm{CTS}$ & $\mathrm{C}_{2} \mathrm{H}_{5}$ & $\mathrm{CH}_{3}$ & $\mathrm{H}$ & $\mathrm{H}$ & 307.89 & 0.78 & 1.31 & 1.45 \\
\hline${ }^{64} \mathrm{Cu}$-CTSM & $\mathrm{C}_{2} \mathrm{H}_{5}$ & $\mathrm{CH}_{3}$ & $\mathrm{CH}_{3}$ & $\mathrm{H}$ & 335.94 & 0.82 & 1.97 & 1.94 \\
\hline${ }^{64} \mathrm{Cu}$-DTS & $\mathrm{C}_{2} \mathrm{H}_{5}$ & $\mathrm{C}_{2} \mathrm{H}_{5}$ & $\mathrm{H}$ & $\mathrm{H}$ & 321.91 & 0.78 & 1.70 & 1.77 \\
\hline${ }^{64} \mathrm{Cu}$-DTSM & $\mathrm{C}_{2} \mathrm{H}_{5}$ & $\mathrm{C}_{2} \mathrm{H}_{5}$ & $\mathrm{CH}_{3}$ & $\mathrm{H}$ & 349.97 & 0.85 & 2.01 & 2.02 \\
\hline${ }^{64} \mathrm{Cu}-\mathrm{PTSE}$ & $\mathrm{CH}_{3}$ & $\mathrm{H}$ & $\mathrm{C}_{2} \mathrm{H}_{5}$ & $\mathrm{H}$ & 335.94 & 0.80 & 1.74 & 1.68 \\
\hline${ }^{64} \mathrm{Cu}-$ PTSM & $\mathrm{CH}_{3}$ & $\mathrm{H}$ & $\mathrm{CH}_{3}$ & $\mathrm{H}$ & 307.89 & 0.74 & 1.52 & 1.56 \\
\hline
\end{tabular}

FIGURE 1. Structure and physicochemical properties of ${ }^{64} \mathrm{Cu}-\mathrm{BTSC}$ complexes. ITLC = instant thin-layer liquid chromatography; ATSE = diacetyl bis(N4-ethylthiosemicarbazone); CTSM = 2,3-pentanedione bis (N4-methylthiosemicarbazone); DTS $=3,4$-hexanedione bis(thiosemicarbazone); DTSM = 3,4-hexanedione bis(N4-methylthiosemicarbazone).

we have therefore investigated the potential of these complexes for identifying hypoxic but viable myocardium. Using biexponential fitting of tracer washout curves in an isolated heart model, we describe the structure-activity relationships for a range of BTSCs, providing guidance for their future development for hypoxia imaging in general and cardiovascular application in particular. We also present the first in vivo preclinical PET imaging, pharmacokinetic, and biodistribution evaluations of 2 complexes we have identified that exhibit better hypoxia selectivity than ${ }^{64} \mathrm{Cu}$-ATSM.

\section{MATERIALS AND METHODS}

\section{Reagents and Gas Mixtures}

All reagents were purchased from Sigma-Aldrich unless otherwise stated. All gas mixtures were purchased from BOC Industrial Gases. Specialist gas mixtures were certified by the manufacturer.

\section{Animals}

Male Wistar rats (220-240 g; B\&K Universal) were used for all experiments. Animal procedures were in accordance with the Animals (Scientific Procedures) Act, U.K., 1986.

\section{Radionuclide Production and Ligand Radiolabeling}

${ }^{64} \mathrm{Cu}$ was produced at the Clinical PET Centre, St. Thomas' Hospital, London, U.K., as previously described. The structures of the

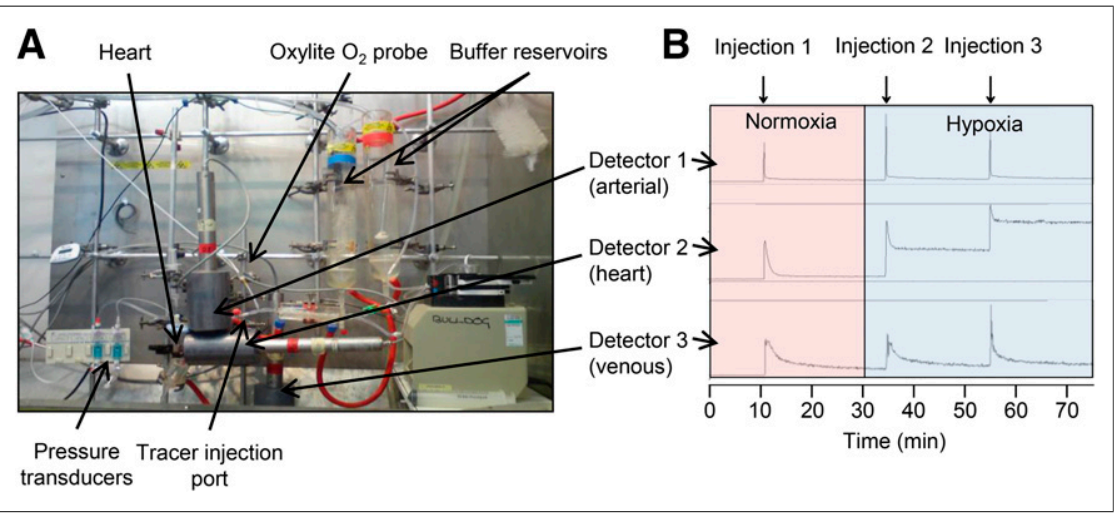

FIGURE 2. (A) Triple- $\gamma$-detector system for monitoring radiotracer passage through Langendorff heart apparatus. (B) Representative time-activity curves from ${ }^{64} \mathrm{Cu}$-ATSM displaying input function in arterial line (detector 1), retention/washout through heart (detector 2), and washout (detector 3).
BTSCs investigated are shown in Figure 1; their syntheses and radiolabeling protocol have also been reported previously $(6,17)$. ${ }^{18} \mathrm{~F}$-fluoride was produced from the ${ }^{18} \mathrm{O}(\mathrm{p}, \mathrm{n}){ }^{18} \mathrm{~F}$ reaction by irradiation of ${ }^{18} \mathrm{O}$-water ( 97 atom\%, Isochem Ltd., with $11-\mathrm{MeV}$ protons from a CTI RDS 112 cyclotron (beam current, $30 \mu \mathrm{A}) .{ }^{18} \mathrm{~F}$-fluoromisonidazole was prepared following a previously reported method (18).

\section{Measurement of ${ }^{64} \mathrm{Cu}$-BTSC Retention Factors and Partition Coefficients}

One microliter of each ${ }^{64} \mathrm{Cu}$-BTSC solution was pipetted onto an instant thin-layer chromatography silica gel strip and developed using ethanol as the mobile phase. Strips were analyzed using a Flow Count instant thin-layer chromatography plate scanner fitted with a $\beta^{-1+}$ detector (B-FC-3600; LabLogic). Rf values and purities were determined using Laura software (version 4.0.3.75; LabLogic). ${ }^{64} \mathrm{Cu}-\mathrm{BTSC}$ partition coefficients were determined using $\mathrm{H}_{2} \mathrm{O}$ or a modified Krebs-Henseleit buffer (KHB, pH 7.4) against octanol, as previously described (19).

\section{The Triple- $\gamma$-Detection System}

We developed a system for characterizing the pharmacokinetics of radionuclide passage through an isolated perfused heart (Fig. 2A), comprising 3 orthogonally oriented lead-collimated $\mathrm{Na} / \mathrm{I} \gamma$ detectors positioned, first, $3 \mathrm{~cm}$ downstream of a radiotracer injection port on the arterial line, $15 \mathrm{~cm}$ upstream of the heart cannula (to provide a radiotracer input function); second, directly opposite the heart itself; and third, over the venous outflow line (to provide an output function). Each was connected to a modified GinaSTAR instant thin-layer chromatography system running Gina software (Raytest Ltd.). Buffer oxygen saturation was monitored continuously by an in-line fluorescent oxygen and temperature probe inserted into the arterial line (Oxylab; Oxford Optronix U.K. Ltd.).

\section{Experimental Protocol}

Rats ( $n=5$ /group) were anesthetized with pentobarbital (100 mg intraperitoneally) and were heparinized (200 IU intraperitoneally), and their hearts were excised and cannulated in the Langendorff mode as previously described (20). They were perfused at a $14 \mathrm{~mL} / \mathrm{min}$ constant flow with $\mathrm{KHB}$ at $37^{\circ} \mathrm{C}$ containing $\mathrm{NaCl}(118.5 \mathrm{mM})$, $\mathrm{NaHCO}_{3}(25 \mathrm{mM})$, D-glucose $(11 \mathrm{mM}), \mathrm{KCl}(8 \mathrm{mM}), \mathrm{CaCl}_{2}$ (2.5 mM), $\mathrm{MgSO}_{4}(1.2 \mathrm{mM})$, and $\mathrm{Na}_{2}$-ethylenediamine tetraacetic acid $(0.5 \mathrm{mM})$ and gassed with $95 \% \mathrm{O}_{2}$ and $5 \% \mathrm{CO}_{2}$, and a left ventricular balloon was used to measure contractile function.

After a 10-min stabilization period, a bolus of radiotracer $(1 \mathrm{MBq}$ in $100 \mu \mathrm{L}$ of $\mathrm{KHB}$ ) was injected into the arterial line. After $20 \mathrm{~min}$, the perfusate was switched to hypoxic KHB from a parallel reservoir gassed with $95 \% \mathrm{~N}_{2}$ and $5 \% \mathrm{CO}_{2}$. Further radiotracer boluses were administered 5 and 25 min after induction of hypoxia. Radiotracer flow through the perfusion rig and heart was monitored by the triple$\gamma$-detector system (Fig. 2B). Coronary effluent was collected at regular intervals and analyzed for lactate content (by a 2300 STAT Plus lactate analyzer; YSI Ltd.) to identify the onset of anaerobic glycolysis, and creatine kinase (by standard spectrophotometric assay (21)) to monitor the extent of tissue necrosis.

\section{Kinetic Profiling of Radiotracer Retention and Elution}

Radiotracer time-activity curves were analyzed with MATLAB (MathWorks). Data were normalized to the maximum peak 
counts after each injection (as previously reported (22)) and were corrected for decay and background activity in the heart $30 \mathrm{~s}$ before each bolus injection. All washout curves described by $f(t)$ were fitted to a biexponential function using least squares:

$$
f(t)=a \times e^{-b \times t}+c \times e^{-d \times t},
$$

where $b$ and $d$ were the slow and fast clearance rate constants (SCR and FCR, respectively) and $a$ and $c$ were the respective weights of the SCR and FCR (22). To evaluate goodness of fit, residuals at each time point were calculated. Tissue retention was calculated as the residual activity in the heart $20 \mathrm{~min}$ after injection as a percentage of the peak activity (percentage injected dose, \%ID), as previously described (10).

\section{In Vivo Imaging and Biodistributions}

PET imaging was performed using a NanoPET/CT preclinical scanner (Mediso). Rats $(n=3$ /group) were anesthetized with isoflurane, a CT scout scan was acquired, and dynamic PET scans covering the thorax were acquired for $30 \mathrm{~min}$, with $6 \mathrm{MBq}$ of either ${ }^{64} \mathrm{Cu}-$ ATSM, ${ }^{64} \mathrm{Cu}$-2,3-pentanedione bis(thiosemicarbazone) (CTS), or ${ }^{64} \mathrm{Cu}$-2,3-butanedione bis(thiosemicarbazone) (ATS) injected intravenously $1 \mathrm{~min}$ into the scan. CT images were then acquired using a $45-\mathrm{kVP} x$-ray source and a $500-\mathrm{ms}$ exposure time in 180 projections, using a pitch of 1.5 with an acquisition time of 5 min to cover the thorax. A final whole-body PET scan was then acquired to obtain biodistribution data ( 3 bed positions, 10 min per position) using a 5-ns coincidence window and a 400- to 600-keV energy window in 1:5 coincidence mode. Data were reconstructed using the following method: ordered-subsets expectation maximization (6 subsets, 6 iterations, $0.4-\mathrm{mm}$ pixel size, $0.585-\mathrm{mm}$ axial resolution). For dynamic analysis, data were rebinned into 30 bins of $1 \mathrm{~min}$ each. After $90 \mathrm{~min}$, rats were culled and tissues were removed, weighed, and counted on a $\gamma$ counter alongside a serial dilution of the injected dose to allow the calculation of tissue uptake as \%ID.

PET data were coregistered with the CT data and analyzed using VivoQuant (inviCRO). Volumes of interest were created for the heart, liver, and kidneys, and the \%ID was calculated for all at each time point.

\section{Statistical Analysis}

Analysis was performed using Prism (GraphPad Software Inc.). All values are expressed as mean $\pm \mathrm{SD}$. All data were analyzed using a 1-way ANOVA, with a Bonferroni adjustment post hoc test or Dunnett test when multiple comparisons were made to a control group.

\section{RESULTS}

Figure 1 summarizes the $\mathrm{R}_{\mathrm{f}}$ values and $\log \mathrm{P}$ values obtained for each ${ }^{64} \mathrm{Cu}$-BTSC. Their lipophilicity increased linearly with molecular weight through alkylation at the $\mathrm{R}^{1}-\mathrm{R}^{4}$ positions. Partition coefficients were unaffected by the use of KHB rather than water as the aqueous phase.

When perfusion was switched from normoxic to hypoxic buffer, afferent buffer $\mathrm{O}_{2}$ saturation fell to less than $20 \mathrm{~mm} \mathrm{Hg}$ within $5 \mathrm{~min}$ and to less than $5 \mathrm{~mm} \mathrm{Hg}$ by $25 \mathrm{~min}$ (Fig. 3). The partial pressure of $\mathrm{O}_{2}$ of fully oxygenated $\mathrm{KHB}$ is approximately $500 \mathrm{~mm} \mathrm{Hg}$, which saturated the Oxylite oxygen probes (Oxford Optronix) during normoxia (they have an operating maximum of $150 \mathrm{~mm} \mathrm{Hg}$ ), but partial pressure of $\mathrm{O}_{2}$ decreased to measurable levels within a minute of switching to hypoxic buffer. Coronary perfusion pressure and left ventricular end diastolic pressure rose progressively from the onset of hypoxia. Developed pressure dropped rapidly and then recovered briefly after approximately $15 \mathrm{~min}$ before declining to zero after $40 \mathrm{~min}$. Lactate release peaked at $0.78 \pm 0.3 \mathrm{nmol} / \mathrm{min}$ after $4 \mathrm{~min}$ of hypoxic buffer perfusion, before falling at a rate mirroring the decline in contractility. Creatine kinase leakage averaged $60 \pm 11 \mu \mathrm{U} / \mathrm{min} / \mathrm{g}$ of wet weight during aerobic perfusion and did not increase during hypoxic buffer perfusion.

BTSC complexes alkylated at $\mathrm{R}^{1}$ and $\mathrm{R}^{2}$ displayed decreasing normoxic tissue retention with decreasing lipophilicity (coefficient of determination, 0.84), with both ${ }^{64} \mathrm{Cu}$-ATS and ${ }^{64} \mathrm{Cu}-$ CTS exhibiting less normoxic tissue retention than ${ }^{64} \mathrm{Cu}-\mathrm{ATSM}$ $(5.8 \pm 1.1$ and $4.3 \pm 0.7 \%$ ID vs. $8.0 \pm 1.7 \%$ ID) (Figs. $4-6$ and Supplemental Figure 1 [supplemental materials are available at http://jnm.snmjournals.org]). During hypoxia, there was no relationship between tracer lipophilicity and tissue retention (coefficient of determination, 0.41 and 0.24 after 5 and $25 \mathrm{~min}$ of hypoxia, respectively). After $5 \mathrm{~min}$ of hypoxia, ${ }^{64} \mathrm{Cu}$-ATS and ${ }^{64} \mathrm{Cu}-\mathrm{CTS}$ both exhibited significantly greater contrast than ${ }^{64} \mathrm{Cu}$-ATSM (9:1 and 10:1 vs. 6:1, respectively), which increased further after $25 \mathrm{~min}$ of hypoxia (14:1 and 17:1 vs. 8:1, respectively).

${ }^{64} \mathrm{Cu}$-pyruvaldehyde bis(N4-ethylthiosemicarbazone) (PTSE) and ${ }^{64} \mathrm{Cu}$-pyruvaldehyde bis(N4-methylthiosemicarbazone) (PTSM) (which are not alkylated at $\mathrm{R}^{2}$ ) had significantly higher normoxic tissue retentions than the other tracers $(54.5 \pm 3.5 \% \mathrm{ID}$ and $63.6 \pm 2.1 \% \mathrm{ID}$, respectively). They also displayed some hypoxia selectivity, with their tissue retention increasing to 86.2 $\pm 7.5 \% \mathrm{ID}$ and 82.6.1 $\pm 5.7 \% \mathrm{ID}$ after $5 \mathrm{~min}$ of hypoxia and to $90.1 \pm 3.3 \% \mathrm{ID}$ and $89.5 \pm 5.2 \% \mathrm{ID}$ after $25 \mathrm{~min}$ of hypoxia $(P<0.05)$.

Tissue retention of ${ }^{64} \mathrm{CuCl}_{2}$ was negligible regardless of the level of tissue oxygenation. ${ }^{18} \mathrm{~F}$-fluoromisonidazole achieved a hypoxia-to-normoxia contrast of 5:1 after $25 \mathrm{~min}$ of hypoxia,

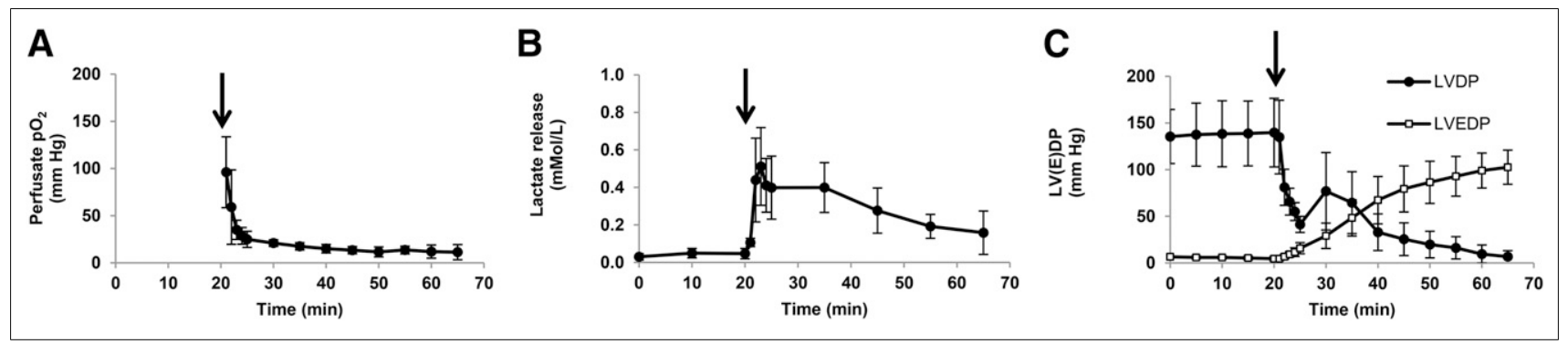

FIGURE 3. Hemodynamic data from isolated rat hearts during $20 \mathrm{~min}$ of normoxic perfusion followed by 45 min of hypoxic perfusion (marked by arrow), showing changes in perfusate partial pressure of $\mathrm{O}_{2}(A)$, lactate washout (B), and left ventricular developed pressure (LVDP) and left ventricular end diastolic pressure (LVEDP) (C). Data are mean $(n=5) \pm$ SD. 


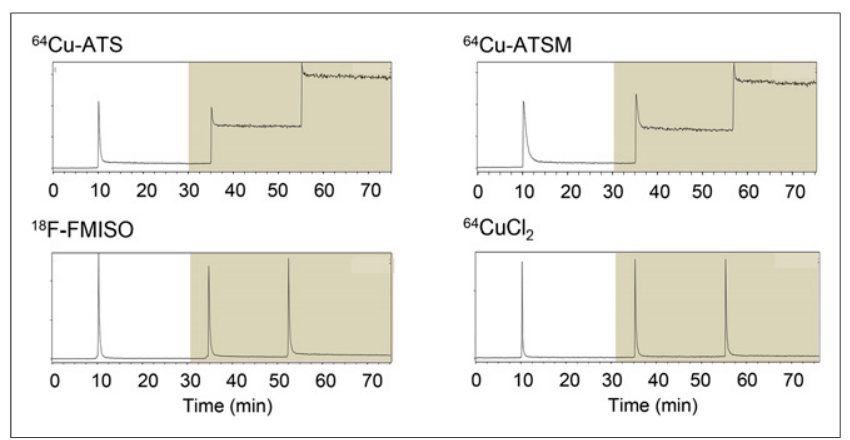

FIGURE 4. Representative time-activity curves showing myocardial clearance and accumulation of ${ }^{64} \mathrm{Cu}$-ATS, ${ }^{64} \mathrm{Cu}$-ATSM, ${ }^{18} \mathrm{~F}$-fluoromisonidazole (FMISO), and ${ }^{64} \mathrm{CuCl}_{2}$ during normoxia (white background) and then hypoxia (gray background). Each spike represents 1-MBq bolus.

but first-pass uptake was extremely low compared with the BTSCs $(2.24 \pm 0.09 \%$ ID).

During normoxia, the weight of the FCR for the $\mathrm{R}^{1}$ and $\mathrm{R}^{2}$ alkylated complexes was greater than 0.8 , whereas for PTSE it was only $0.4 \pm 0.03$. After $5 \mathrm{~min}$ of hypoxia, the weight of the FCR for the $\mathrm{R}^{1}$ and $\mathrm{R}^{2}$ alkylated complexes declined such that it was approximately equal to the weight of the SCR (while the weight of the FCR for ${ }^{64} \mathrm{Cu}$-PTSE was still 0.76). After $25 \mathrm{~min}$ of hypoxia, the weight of the SCR increased to 0.6 for all tracers. The weight of the SCR for ${ }^{64} \mathrm{CuCl}_{2}$ was negligible in all cases. The SCR of the BTSCs was approximately 100 times smaller than the FCR during normoxia and was comparable among ${ }^{64} \mathrm{Cu}-$ ATS, ${ }^{64} \mathrm{Cu}$-CTS, ${ }^{64} \mathrm{Cu}$-diacetyl bis(N4-methylthiosemicarbazone), and ${ }^{64} \mathrm{Cu}-3,4-$ hexanedione bis(thiosemicarbazone) (averaging $0.01 \pm 0.001 \mathrm{~min}^{-1}$ ), whereas it was lower for the more lipophilic complexes $\left(2 \pm 0.1 \times 10^{-3}\right.$ and $2.3 \pm 0.1 \times 10^{-3} \mathrm{~min}^{-1}$ for ${ }^{64} \mathrm{Cu}-2,3$-pentanedione bis(N4-methylthiosemicarbazone) and ${ }^{64} \mathrm{Cu}$-ATSE, respectively). The normoxic FCR of the BTSCs decreased (i.e., clearance was slower) with increasing lipophilicity, with ${ }^{64} \mathrm{Cu}$-ATS $\left(3.7 \pm 0.2 \mathrm{~min}^{-1}\right)$ and ${ }^{64} \mathrm{Cu}$-CTS $(3.1 \pm$ $0.3 \mathrm{~min}^{-1}$ ) having markedly greater FCRs than ${ }^{64} \mathrm{Cu}$-ATSM $\left(1.2 \pm 0.2 \mathrm{~min}^{-1}\right)$ (Fig. 6). The FCR increased with hypoxic duration for all complexes except ${ }^{64} \mathrm{Cu}$-PTSE. The FCR of ${ }^{64} \mathrm{CuCl}_{2}$ was at least twice that of any BTSC complex $\left(10 \pm 0.7 \mathrm{~min}^{-1}\right)$ and decreased during hypoxia. It was not possible to calculate the clearance rates for ${ }^{64} \mathrm{Cu}$-PTSM (or ${ }^{64} \mathrm{Cu}$-DTSM during normoxia) because they did not reach steady state. For the less lipophilic tracers, the SCR progressively fell with increasing duration and severity of hypoxia

In vivo, cardiac ${ }^{64} \mathrm{Cu}$-ATSM, ${ }^{64} \mathrm{Cu}-\mathrm{CTS}$, and ${ }^{64} \mathrm{Cu}$-ATS retention fell to $0.6 \%$ of injected dose within 6 min of injection (Fig. 7). ${ }^{64} \mathrm{Cu}-\mathrm{CTS}$ retention within the heart averaged $0.54 \pm 0.02 \% \mathrm{ID}$ over the last $20 \mathrm{~min}$ of the scan, significantly lower than for ${ }^{64} \mathrm{Cu}-$ ATS $\left(0.63 \pm 0.2 \%\right.$ ID) and ${ }^{64} \mathrm{Cu}$-ATSM $(0.67 \pm 0.01 \%$ ID, $P<0.05)$. This finding was confirmed by ex vivo biodistribution 90 min after injection, when cardiac retention of ${ }^{64} \mathrm{Cu}-\mathrm{CTS}$ was significantly lower than that of the other 2 tracers $(0.13 \pm 0.02 \%$ ID vs. $0.25 \pm 0.04 \% \mathrm{ID}$ for ${ }^{64} \mathrm{Cu}$-ATSM and $0.24 \pm 0.03 \% \mathrm{ID}$ for ${ }^{64} \mathrm{Cu}$-ATS, $\left.P<0.05\right)$. The primary route of excretion of all $3 \mathrm{com}-$ plexes appeared to be hepatic, although both the imaging data and the ex vivo biodistributions suggested that a larger fraction of ${ }^{64} \mathrm{Cu}-\mathrm{CTS}$ clears renally.

\section{DISCUSSION}

We have identified 2 complexes, ${ }^{64} \mathrm{Cu}$-ATS and ${ }^{64} \mathrm{Cu}-\mathrm{CTS}$, that demonstrate greater hypoxic-to-normoxic tissue contrast and superior pharmacokinetics (faster clearance from and lower retention in normoxic tissue) than the current lead hypoxia-imaging agents, ${ }^{64} \mathrm{Cu}$-ATSM and ${ }^{18} \mathrm{~F}$-fluoromisonidazole.

As has previously been shown in isolated cells $(5,9)$, we demonstrated that lowering the redox potential of ${ }^{64} \mathrm{Cu}$-BTSC complexes by alkylating them at both the $\mathrm{R}^{1}$ and the $\mathrm{R}^{2}$ positions results in greater hypoxia selectivity than that of ${ }^{64} \mathrm{Cu}$-PTSE and ${ }^{64} \mathrm{Cu}$-PTSM, which are alkylated at only one of these positions (6). Our pharmacokinetic data show that the FCR is the primary determinant of BTSC kinetics in normoxic tissue, whereas the SCR dominates during hypoxia. This finding is consistent with a previous description of ${ }^{99 \mathrm{~m}} \mathrm{Tc}-\mathrm{HL} 91$ pharmacokinetics that defines the FCR as an index of tracer washout through the vasculature and the SCR as an indicator of tracer trapping (23). As tracer washout increases with decreasing lipophilicity in normoxic tissue, reducing the lipophilicity of these complexes seems to be a useful strategy for improving their selectivity. ${ }^{64} \mathrm{Cu}$-ATS and ${ }^{64} \mathrm{Cu}-\mathrm{CTS}$, which have a redox potential similar to ${ }^{64} \mathrm{Cu}$-ATSM but clear more quickly because of their lower lipophilicity, gain a significant advantage in terms of delivering greater contrast more rapidly after injection. They appear sufficiently lipophilic to cross cell membranes but not lipophilic enough to be retained within them for a significant time. This characteristic may also aid their tissue penetration by allowing them to diffuse further between cells without becoming detained in cell membranes close to the vasculature. The shift in dominant weights suggests that the importance of the FCR in governing tracer kinetics diminishes with increasing hypoxic severity, in favor of tracer trapping represented
FIGURE 5. (A) Tissue retention of ${ }^{64} \mathrm{Cu}$-BTSC complexes, ${ }^{18} \mathrm{~F}$-fluoromisonidazole, and ${ }^{64} \mathrm{CuCl}_{2}$ during normoxia and hypoxia. Asterisk indicates significant difference from corresponding normoxic control $(P<0.05)$. (B) Normoxic-to-hypoxic contrast ratios as calculated from A. Asterisk indicates significant difference from corresponding ${ }^{64} \mathrm{Cu}$-ATSM values $(P<0.05)$. Data are mean $(n=5) \pm$ SD. ATSE = diacetyl bis(N4-ethylthiosemicarbazone); CTSM = 2,3-pentanedione bis (N4-methylthiosemicarbazone); DTS $=3,4$-hexanedione bis(thiosemicarbazone); DTSM $=3,4$ hexanedione bis(N4-methylthiosemicarbazone); FMISO = fluoromisonidazole.

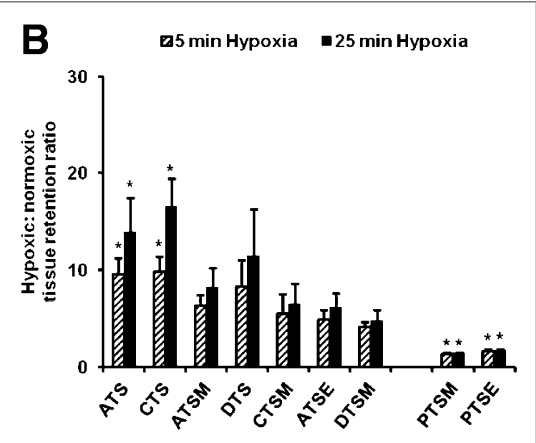

Improved CompleXes for Hypoxia Imaging • Handley et al. 


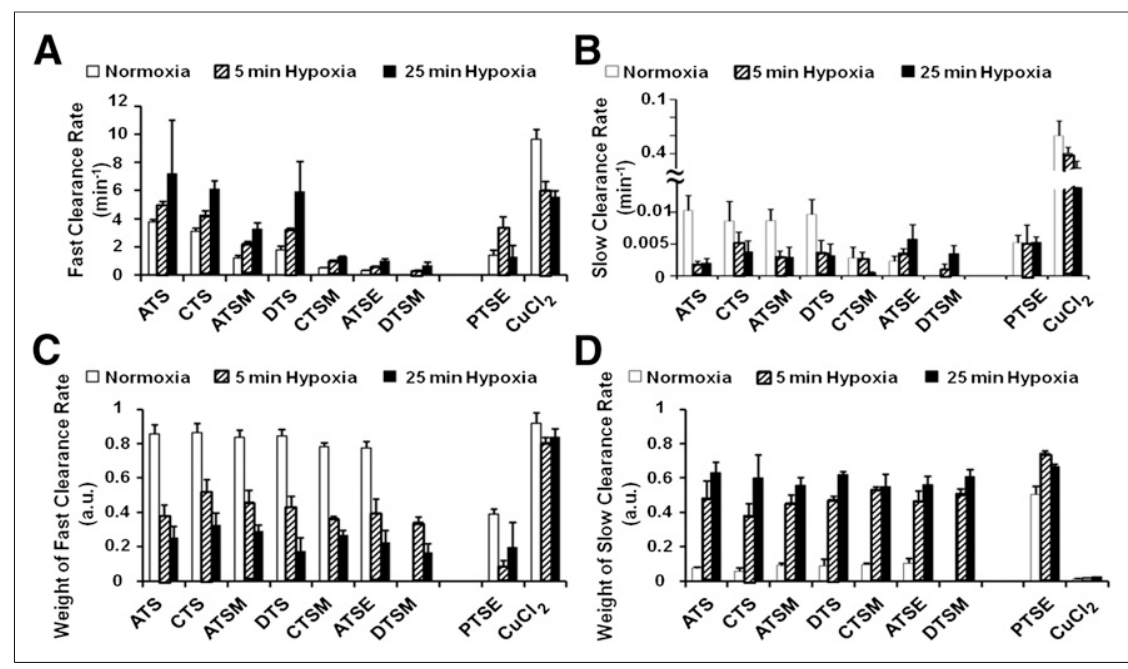

FIGURE 6. Fast (A) and slow (B) rates of tracer clearance from myocardium (and their respective weights, C and D). Data are mean $(n=5) \pm$ SD. a.u. = arbitrary units. ATSE = diacetyl bis(N4ethylthiosemicarbazone); CTSM = 2,3-pentanedione bis(N4-methylthiosemicarbazone); DTS = 3,4hexanedione bis(thiosemicarbazone); DTSM = 3,4-hexanedione bis(N4-methylthiosemicarbazone).

by the SCR. We currently interpret this shift as a reflection of the increasing hypoxic fraction of cells beyond the threshold for tracer retention in each case. It is interesting that the FCR appears to increase with increasing hypoxic duration and severity; we do not yet have an explanation.

In vivo, ${ }^{64} \mathrm{Cu}-\mathrm{CTS}$ is retained less in normoxic myocardium than is ${ }^{64} \mathrm{Cu}-\mathrm{ATSM}$, consistent with our isolated heart data. We are currently unable to perform electrocardiography-gated preclin-

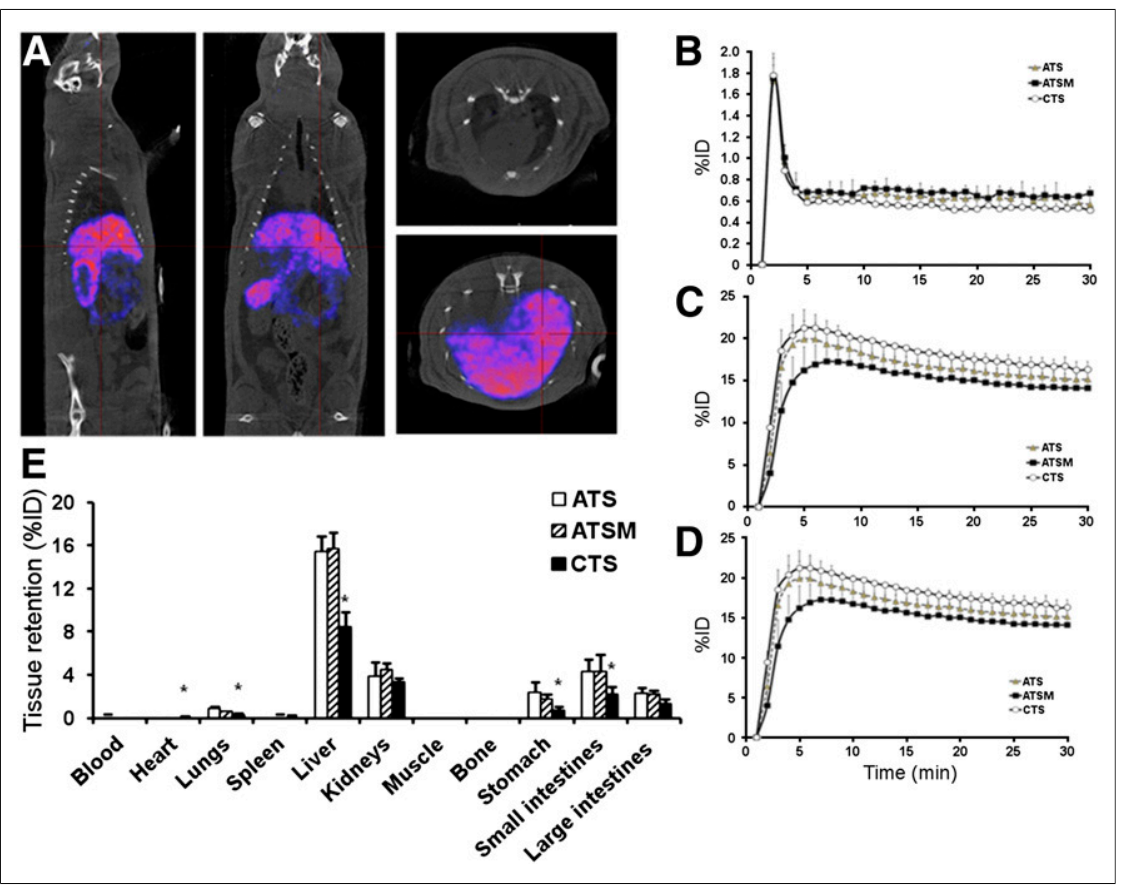

FIGURE 7. (A) PET/CT images of healthy rat $30 \mathrm{~min}$ after injection with ${ }^{64} \mathrm{Cu}-\mathrm{CTS}$ (5 MBq in 200 $\mu \mathrm{L})$. (B-D) Time-activity curves showing tracer pharmacokinetics of ${ }^{64} \mathrm{Cu}-\mathrm{ATS},{ }^{64} \mathrm{Cu}-\mathrm{ATSM}$, and ${ }^{64} \mathrm{Cu}-\mathrm{CTS}$ in heart, liver, and kidneys, respectively. (E) Tissue biodistribution of each tracer $90 \mathrm{~min}$ after injection. Data are mean $(n=3) \pm$ SD. Asterisk indicates significant difference from ${ }^{64}$ Cu-ATSM $(P<0.05)$. ical PET imaging (which would enable us to distinguish myocardium from ventricular blood pool), but our ex vivo biodistribution data confirm our PET data. The main nontarget organs that may confound myocardial hypoxia imaging are liver, lung, and blood pool. Our data suggest that ${ }^{64} \mathrm{Cu}-\mathrm{CTS}$ clears from these tissues more quickly than ${ }^{64} \mathrm{Cu}$-ATSM (and equally quickly from blood) - a factor that may also enhance the utility of ${ }^{64} \mathrm{Cu}-\mathrm{CTS}-$ but it is unfortunately not possible to confirm enhanced renal clearance because we did not include bladder or urine samples in our biodistribution analysis.

Although PET is unlikely to be the cardiologist's first choice, in terms of speed, convenience, or cost, for characterizing ischemic myocardium immediately after an acute ischemic event, we suggest that this class of tracers exhibits unique potential in identifying chronic cardiac hypoxic syndromes such as those mentioned in our introduction, which are more difficult to characterize by other means $(3,4)$. It is an advantage of these tracers that they require biologic reduction for their intracellular trapping and, as such, are retained within only viable (and potentially salvageable) tissue (12). It is not currently known whether these complexes all have the same sensitivity threshold with respect to degree of hypoxia; this is a critical consideration for their clinical utility and will form the next phase of our evaluation of these complexes.

The biggest challenge to the development of this class of complexes now seems to be that although those currently available vary widely with respect to lipophilicity, they fall into only 3 groups with respect to redox potential (6): ${ }^{64} \mathrm{Cu}-\mathrm{GTS}$ and ${ }^{64} \mathrm{Cu}-\mathrm{GTSM}$ have redox potentials at $-0.43 \mathrm{~V}$ versus $\mathrm{Ag} / \mathrm{AgCl}$ and are not hypoxia-selective; ${ }^{64} \mathrm{Cu}-\mathrm{PTSM}$ and ${ }^{64} \mathrm{Cu}-$ PTSE have redox potentials of $-0.53 \mathrm{~V}$ and $-0.52 \mathrm{~V}$, respectively, and are weakly hypoxia-selective; whereas the rest of the complexes described here have redox potentials of $-0.58 \mathrm{~V}$ and $-0.59 \mathrm{~V}$ and are selective for the extreme hypoxia that we induce in this heart model. It is likely that trapping is a balance between the dissociation rate of reduced complexes and the reoxidation rate by oxygen, which have yet to be quantified.

${ }^{64} \mathrm{Cu}$-PTSM has been previously investigated as a perfusion agent for monitoring myocardial blood flow (24), on the assumption that its trapping is nonselective: its relatively low redox potential allows it to become reduced and dissociate in normoxic as well as hypoxic tissue (6). Our data confirm previous reports that tissue retention of ${ }^{64} \mathrm{Cu}$ from ${ }^{64} \mathrm{Cu}-\mathrm{PTSM}$ and ${ }^{64} \mathrm{Cu}$ PTSE is also oxygen-sensitive (though less 
so than the complexes alkylated at both $\mathrm{R}^{1}$ and $\mathrm{R}^{2}$ ). This finding suggests either that the reduction of these tracers by normoxic tissue is not maximal or that a proportion of the reduced complex may be reoxidized by oxygen, allowing some tracer to escape the myocardium intact. Hypoxia either increases the efficiency of tracer reduction or abolishes the residual capacity for these tracers to be reoxidized, or both. Whichever is the case, their use as perfusion imaging agents should clearly be chosen with caution.

To screen and characterize radiotracer kinetics and retention characteristics in isolated perfused rat hearts, we developed a triple- $\gamma$-detection system that builds on one previously described by Fujibayashi et al. (10). It allows the simultaneous monitoring of tracer input, cardiac retention, and washout in a beating heart model characterized in terms of contractility, arterial oxygen concentration, cardiac metabolism, and viability. We have confirmed the extent of hypoxia induced by direct measurement of perfusion buffer oxygen saturation, as well as its biologic impact. The onset of lactate production and lack of creatine kinase release confirms these hearts as biochemically compromised, but viable and potentially salvageable, which we believe represents an appropriate target for the first screening of these complexes (3). Because of the rapid first-pass kinetics of these tracers, it was essential to obtain a true postinjection peak in the counts detected from the heart to enable accurate quantification of tracer retention as \% ID (22). Boluses of ${ }^{64} \mathrm{CuCl}_{2}$, our most rapidly clearing tracer, were registered in the heart detector within $3 \mathrm{~s}$ of injection, with a peak lasting $1 \mathrm{~s}$. To ensure we were able to accurately capture the injection peak of all radiotracers, we therefore sampled at $5 \mathrm{~Hz}$. In the future, we may be able to use the arterial line detector to provide an input function for more detailed pharmacokinetic models, but we are still developing this approach.

Although hypoxia is a facet of ischemia, and the effects of the 2 phenomena are practically often difficult to resolve, they should not be used interchangeably (3). We have specifically induced hypoxia in this experimental model because maintaining coronary flow constant greatly simplifies pharmacokinetic modeling. We demonstrated that these tracers respond to hypoxia, and it is established that ${ }^{64} \mathrm{Cu}$-ATSM responds in a similar manner to the hypoxic component of the ischemic insult (24). The extent to which the pharmacokinetics of these tracers are altered by other pathophysiologic processes occurring during ischemia, such as waste product accumulation and acidosis, changes in intracellular redox status, rapid depletion of energy substrates, and the effect of poor perfusion itself, remains to be fully characterized $(3,25)$.

The kinetic analysis used in this study has some limitations. The variability in the estimation of rate constants and their amplitudes increased as signal-to-noise ratio (SNR) decreased because of radioactive decay. It was also not possible to accurately estimate the SCR from tracers with slow washout characteristics (such as ${ }^{64} \mathrm{Cu}-\mathrm{PTSM}$ ) within the time course of our current protocol. We therefore calculated tissue tracer retention as a percentage of injected dose after $20 \mathrm{~min}$ (as has been previously done), rather than as the ratio between the SCR amplitude and the sum of the SCR and FCR amplitudes. Although this choice introduces some time dependency into our values, it also highlights tracers that wash out more completely by $20 \mathrm{~min}$, which as we show here, is a desirable attribute. The observed relative shifts between FCR and SCR suggest that dynamic imaging or parametric map- ping may be able to provide more detailed information on the behavior of these tracers and aid data interpretation. It may, for example, enable the correction of uptake values for perfusion, which has been a consistent problem when interpreting hypoxia tracer uptake in tissue that is both hypoxic and flow-restricted (26).

\section{CONCLUSION}

We have identified 2 complexes, ${ }^{64} \mathrm{Cu}$-ATS and ${ }^{64} \mathrm{Cu}$-CTS, that exhibit better pharmacokinetic properties and hypoxia selectivities than the current leading hypoxia imaging agents, ${ }^{64} \mathrm{Cu}$-ATSM and ${ }^{18}$ F-fluoromisonidazole. Their ex vivo pharmacokinetics and in vivo biodistribution confirm them as a potentially useful advancement of this class of compounds warranting further characterization. The basis of this improvement is that decreasing the lipophilicity of these complexes, without altering their reduction potentials, improves their rate of washout from normoxic tissues and increases hypoxic-to-normoxic tissue contrast.

\section{DISCLOSURE}

The costs of publication of this article were defrayed in part by the payment of page charges. Therefore, and solely to indicate this fact, this article is hereby marked "advertisement" in accordance with 18 USC section 1734. This work was funded by an Engineering and Physical Sciences Research Council PhD studentship (MGH) and a British Heart Foundation project grant (PG/10/20/ 28211), with the support of the National Institute for Health Research (NIHR) Biomedical Research Centre at Guy's and St. Thomas' NHS Foundation Trust and King's College London, the Centre of Excellence in Medical Engineering funded by the Wellcome Trust and EPSRC under grant WT088641/Z/09/Z, and the KCL and UCL Comprehensive Cancer Imaging Centre funded by CRUK and EPSRC in association with the MRC and DoH. The views expressed are those of the authors and not necessarily those of the NHS, the NIHR, or the Department of Health. No other potential conflict of interest relevant to this article was reported.

\section{REFERENCES}

1. Sabbah HN, Sharov VG, Goldstein S. Cell death, tissue hypoxia and the progression of heart failure. Heart Fail Rev. 2000;5:131-138.

2. Lanza GA, Crea F. Primary coronary microvascular dysfunction: clinical presentation, pathophysiology, and management. Circulation. 2010;121:2317-2325.

3. Handley MG, Medina RA, Nagel E, Blower PJ, Southworth R. PET imaging of cardiac hypoxia: opportunities and challenges. J Mol Cell Cardiol. 2011;51: 640-650.

4. Sinusas AJ. The potential of myocardial imaging with hypoxia markers. Semin Nucl Med. 1999;29:330-338.

5. Dearling JLJ, Lewis JS, Mullen GED, Rae MT, Zweit J, Blower PJ. Design of hypoxia-targeting radiopharmaceuticals: selective uptake of copper-64 complexes in hypoxic cells in vitro. Eur J Nucl Med. 1998;25:788-792.

6. Dearling JL, Lewis J, Mullen G, Welch M, Blower P. Copper bis(thiosemicarbazone) complexes as hypoxia imaging agents: structure-activity relationships. J Biol Inorg Chem. 2002;7:249-259.

7. Dearling JLJ, Lewis JS, McCarthy DW, Welch MJ, Blower PJ. Redox-active metal complexes for imaging hypoxic tissues: structure-activity relationships in copper(II) bis(thiosemicarbazone) complexes. Chem Comms. 1998;22:2531-2532.

8. Lewis JS, McCarthy DW, McCarthy TJ, Fujibayashi Y, Welch MJ. Evaluation of ${ }^{64} \mathrm{Cu}-\mathrm{ATSM}$ in vitro and in vivo in a hypoxic tumor model. $\mathrm{J} \mathrm{Nucl} \mathrm{Med}$. 1999;40:177-183.

9. Handley MG, Medina RA, Paul RL, Blower PJ, Southworth R. Demonstration of the retention of ${ }^{64} \mathrm{Cu}$-ATSM in cardiac myocytes using a novel incubation chamber for screening hypoxia-dependent radiotracers. Nucl Med Commun. 2013;34:1015-1022.

10. Fujibayashi Y, Taniuchi H, Yonekura Y, Ohtani H, Konishi J, Yokoyama A. Copper62-ATSM: a new hypoxia imaging agent with high membrane permeability and low redox potential J Nucl Med. 1997;38:1155-1160. 
11. Dence CS, Ponde DE, Welch MJ, Lewis JS. Autoradiographic and small-animal PET comparisons between ${ }^{18} \mathrm{~F}$-FMISO, ${ }^{18} \mathrm{~F}$-FDG, ${ }^{18} \mathrm{~F}$-FLT and the hypoxic selective ${ }^{64} \mathrm{Cu}$-ATSM in a rodent model of cancer. Nucl Med Biol. 2008;35: 713-720.

12. Lewis JS, Herrero P, Sharp TL, et al. Delineation of hypoxia in canine myocardium using PET and copper(II)-diacetyl-bis(N(4)-methylthiosemicarbazone). J Nucl Med. 2002;43:1557-1569.

13. Kositwattanarerk A, Oh M, Kudo T, et al. Different distribution of ${ }^{62} \mathrm{Cu}$ ATSM and ${ }^{18}$ F-FDG in head and neck cancers. Clin Nucl Med. 2012;37:252-257.

14. Lewis JS, Laforest R, Dehdashti F, Grigsby PW, Welch MJ, Siegel BA. An imaging comparison of ${ }^{64} \mathrm{Cu}$-ATSM and ${ }^{60} \mathrm{Cu}$-ATSM in cancer of the uterine cervix. J Nucl Med. 2008;49:1177-1182.

15. Takahashi N, Fujibayashi Y, Yonekura Y, et al. Copper-62 ATSM as a hypoxic tissue tracer in myocardial ischemia. Ann Nucl Med. 2001;15:293-296.

16. McQuade $\mathrm{P}$, Martin $\mathrm{KE}$, Castle TC, et al. Investigation into ${ }^{64} \mathrm{Cu}$-labeled bis (selenosemicarbazone) and bis(thiosemicarbazone) complexes as hypoxia imaging agents. Nucl Med Biol. 2005;32:147-156.

17. Blower PJ, Lewis JS, Zweit J. Copper radionuclides and radiopharmaceuticals in nuclear medicine. Nucl Med Biol. 1996;23:957-980.

18. Oh SJ, Chi DY, Mosdzianowski C, et al. Fully automated synthesis of $\left[{ }^{18} \mathrm{~F}\right]$ fluoromisonidazole using a conventional [ ${ }^{18}$ F]FDG module. Nucl Med Biol. 2005;32:899-905.
19. John EK, Green MA. Structure-activity relationships for metal-labeled blood flow tracers: comparison of keto aldehyde bis(thiosemicarbazonato)copper(II) derivatives. J Med Chem. 1990;33:1764-1770.

20. Southworth R, Garlick PB. Dobutamine responsiveness, PET mismatch, and lack of necrosis in low-flow ischemia: is this hibernation in the isolated rat heart? Am J Physiol Heart Circ Physiol. 2003;285:H316-H324.

21. Urdal P, Stromme JH. Effects of Ca, Mg, and EDTA on creatine kinase activity in cerebrospinal fluid. Clin Chem. 1979;25:147-150.

22. Ng CK, Sinusas AJ, Zaret BL, Soufer R. Kinetic analysis of technetium-99mlabeled nitroimidazole (BMS-181321) as a tracer of myocardial hypoxia. Circulation. 1995;92:1261-1268.

23. Okada RD, Johnson G III, Nguyen KN, Edwards B, Archer CM, Kelly JD. ${ }^{99 m}$ Tc-HL91: effects of low flow and hypoxia on a new ischemia-avid myocardial imaging agent. Circulation. 1997;95:1892-1899.

24. Shelton ME, Green MA, Mathias CJ, Welch MJ, Bergmann SR. Kinetics of copper-PTSM in isolated hearts: a novel tracer for measuring blood flow with positron emission tomography. J Nucl Med. 1989;30:1843-1847.

25. Dearling JLJ, Packard AB. Some thoughts on the mechanism of cellular trapping of Cu(II)-ATSM. Nucl Med Biol. 2010;37:237-243.

26. Wood KA, Honess DJ, Maxwell RJ, et al. Evaluation of the effects of blood flow on ${ }^{64} \mathrm{Cu}$-ATSM uptake in a rodent tumour model [abstract]. Clin Oncol. 2007; 19(suppl):S50. 